\title{
Os intelectuais e as representações da nação: um sertão chamado Brasil
}

\author{
Intellectuals and representations of the nation: \\ a wilderness called Brazil
}

\author{
Marcos Cezar de Freitas \\ Universidade São Francisco \\ Rua Sete de Setembro, 407 \\ 12914-080 Bragança Paulista — SP Brasil \\ Mexoacf@uol.com.br
}

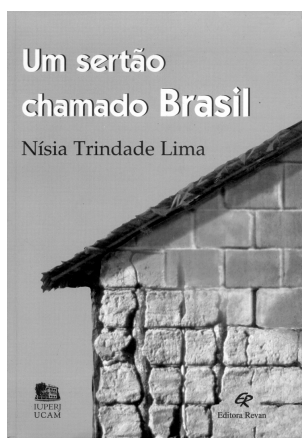

Nísia Trindade Lima Um sertão chamado Brasil

Rio de Janeiro, Renavan/Iuperj-Ucam, 222 p., 1999
A chamada história das mentalidades deixou, a despeito do quanto as tendências investigativas vivem num interminável estar e não estar, um roteiro metodológico cuja fertilidade raramente é aproveitada tanto pelos historiadores de ofício quanto pelos profissionais das ciências sociais. As atitudes humanas diante da morte, ou da vida, ou da festa, ou do inesperado, ou do constante e quase permanente compõem um acervo diante do qual o leitor pode observar o quanto as 'continuidades' requisitam extraordinárias habilidades analíticas para que se manifestem, nos textos, com a mesma contundência com a qual interferem no quotidiano das pessoas.

Um sertão chamado Brasil, de Nísia Trindade Lima, é um exemplar raro da habilidade analítica em captar a renitência e a força de uma metáfora geográfica na (con)formação de representações sobre a identidade nacional de um país considerado invariavelmente em conflito com o próprio vir-a-ser.

O desvelamento das representações de uma identidade permanentemente revelada como incompleta, ou ao aguardo de sua própria refundação, é um processo investigado pela autora num impressionante exercício de observar observadores. Isso torna possível proceder à exegese das mentalidades modernizadoras inconformadas com os 'danos de origem' e com as distâncias irredutíveis entre os muitos Brasis.

O texto de Nísia não é um inventário de interpretações. É, ao contrário, uma interpelação aos inventários para que se revelem como objeto das tramas através das quais os intelectuais percebem a modernidade e representam, no ato mesmo de 'percebê-la', o lugar onde estão.

Um sertão chamado Brasil organiza para o leitor as expressões da convivência conflituosa de dimensões tradicionais e modernas (p.26), mas não o faz lançando mão do 'estado da arte' de um debate. O que a autora faz é a lavra das fundações mais duradouras do pensamento republicano brasileiro, ou seja, aquelas elaborações mentais que insistiram na existência dos dois Brasis. As fundações escavadas nas arqueologias de Nísia ressurgem em estado bruto e com o mesmo talhe conceitual que Quentin Skinner utiliza para escavar a história das idéias 'modernas'. Só que a autora fundamenta o pensamento social brasileiro num de seus aspectos mais densos: o das junções entre os dualismos interpretativos e as sagas civilizadoras. Procede à arqueologia das fundações para mostrar que a distância entre 
modernidade e modernização, como sugere Raimundo Faoro, é também um desvão no qual se escondem inúmeros empreendimentos analíticos levados a efeito nos séculos XIX e XX.

Nesse sentido, nos momentos nos quais a autora anuncia os caminhos que, de antemão, serão recusados, o leitor já se percebe diante de um roteiro vigoroso. Nísia recusa com propriedade os chamados marcos de cientificidade diante dos quais as ciências sociais habitualmente prestam contas. Isso quer dizer que a trama recomposta pela autora não se apresenta como o passado pré-científico da investigação sociológica brasileira, que supostamente antecederia o momento da institucionalização das práticas investigativas nos domínios das ciências sociais, mormente na Universidade de São Paulo (pp. 29, 159). O plano da autora é o das continuidades. Sem este não haveria como mergulhar no pathos do intelectual inconformado com a distância entre civilização e barbárie; aturdido com a questão racial e desconfiado da herança colonial que nos fez desde todo sempre arcaicos ou, no mínimo, pré-modernos.

A fronteira e o homem fronteiro (p.41) e as conseqüências analíticas do estranhamento e da distância compuseram para a sociedade brasileira um painel de reconhecimento para o lugar proeminente da opinião científica, esta urdida nas ciências médicas, jurídicas e de engenharia. Mas Nísia trabalha com matrizes da elaboração da metáfora sertão como metáfora da nação como um todo (ou como um nada). Por isso, a autora sinaliza que as missões civilizatórias e o projeto de incorporação dos sertões (p. 65) são reveladoras da intelectualidade portadora de uma 'cultura heróica', e aí não hesita em anunciar quais são as matrizes: Euclides da Cunha, Cândido Rondon e Oswaldo Cruz (p. 67). A procura por essas matrizes já havia conduzido a análise a um questionamento agudo: "Como foi retratado o homem brasileiro? Como os intelectuais se colocaram diante de uma sociedade vista tantas vezes como oscilante entre estados de anomia e laços solidários estritamente verticais..." (p. 32).

Para responder a essa questão, o livro conduz o leitor às polêmicas que dividiram iberistas e americanistas (p. 48); às arquiteturas políticas e teóricas da década de 1920, quando se encontraram educadores e sanitaristas (p. 45); às ambivalências euclidianas que apostavam "num projeto civilizatório na defesa da ciência e do progresso e (na) crítica a uma modernização excludente e inautêntica". (p. 49). Mas a narrativa conduz o leitor, acima de tudo, à compreensão de um círculo vicioso de determinismos com os quais as tipologias do Brasil arcaico/moderno; real/legal; litorâneo/sertanejo passaram a representar 'o outro' (ainda que brasileiro) como objeto de conquista.

Vale a pena reproduzir um trecho que permite ao leitor identificar o roteiro cognitivo de tantos dualismos: "sertão: o território do vazio, o domínio do desconhecido, o espaço ainda não preenchido pela colonização. É, por isso, o mundo da desordem domínio da barbárie, da selvageria, do diabo. Ao mesmo tempo, se conhecido, pode ser ordenado através da ocupação e da colonização, deixando de ser sertão para constituir-se em região colonial" (pp. 57-8). Por isso, a pertinência da retomada da fala de Afrânio Peixoto, segundo a qual o sertão começaria no término da avenida Central (p. 60).

Mas a imagem do sertão como patologia faz-se acompanhar das imagens do sertão portador de uma nova brasilidade (pp. 62-3). Em razão disso, quando a autora afirma que "a higiene é apontada como 
conhecimento e conjunto de práticas capazes de fazer a mediação entre o estado natural e a civilização" (p. 110) está, na realidade operando a síntese com a qual desnudou uma intelectualidade em seu próprio 'fazer ciência', projetando a ponte entre o sertão e a cidade, vale dizer, entre um brasileiro e outro brasileiro, entre o autêntico e o racional.

Nesse sentido, o rastreamento das metáforas de e sobre o sertanejo conduz a autora a todos os seus 'heterônimos', entre os quais, talvez o Jeca tenha conseguido fazer-se mais famoso. Mas, para quem julga que esse empreendimento analítico se encerra na minudência das fundações, o livro não cessa de surpreender.

A autora flagra a dualidade dos dois Brasis numa longevidade quase impressionista. A metáfora do sertão bárbaro transmuta-se na representação do rústico resistente à mudança (p. 172); ou do rústico à mercê do messianismo (pp. 185-6). Se, anteriormente, o médico despontara nesse cenário como etnógrafo (p. 121), será o sociólogo (devidamente institucionalizado) o personagem a fazer do homem interiorano um componente das suas metáforas de aceleração do tempo.

Não será por acaso que Roger Bastide fará par, nesse cenário, com Florestan Fernandes, Maria Isaura Pereira de Queiroz e Antonio Candido. O sertão e os dois Brasis motivarão inúmeros movimentos de 'volta a Euclides da Cunha' nas décadas de 1950 e 1960.

Ocorrem-me dois marcos interpretativos que, uma vez trazidos ao diálogo, comprovam a acuidade do olhar de Nísia. Refiro-me a Dois Brasis, de Jacques Lambert e Brasil, terra de contrastes, de Roger Bastide.

Do primeiro, pode-se evocar a seguinte observação:

A situação no Brasil não é tão séria porque não se trata nem de duas raças nem de dois povos formando duas sociedades diferentes, mas de indivíduos que professam a mesma religião, falam a mesma língua e têm a mesma nacionalidade, a mesma história e a consciência da sua solidariedade. Não há qualquer obstáculo, além do econômico, à transição de uma sociedade para outra, o que não impede que o Brasil precise urgentemente difundir por todo o país os níveis e métodos de vida das regiões evoluídas (Lambert, 1973, p. 106-7).

E de Bastide (1971, p. 232) pode-se recuperar:

Todos os contrastes de terra e vegetação, de raça e de etnias, de costumes e de estilos permanecem brasileiros. Todas as oposições de velocidade e lentidão não impedem que o tempo, que ora parece estagnar preguiçoso, ora se precipita para o futuro, seja sempre o mesmo tempo brasileiro. Até agora, foi focalizada a harmonização de contrários, água e fogo, açúcar e café, litoral e sertão, e verificou-se que as civilizações antagônicas, a do gaúcho no Sul e a do vaqueiro no Norte, a do fazendeiro e a do industrial, a do negro e a do imigrante, são antes complementares do que antagônicas. Mas há uma unidade mais profunda do que a da simples complementaridade entre elas; por toda parte, são encontrados os mesmos problemas fundamentais, impostos pelo meio geográfico ou herdados da história .

São dois exemplares da impressão dualista a chamar os tempos históricos e a exigir dos mesmos um movimento de equiparação. Dois reclamos por uniformidade a mostrar que, por quase um século, quando se falava do sertão, tinha-se em mente todo um país. 
Um sertão chamado Brasil repõe com grande lucidez o fato de que as ciências sociais brasileiras, independentemente da fase pela qual estivessem passando, independentemente do grau de institucionalização a que estivessem submetidas, não deixaram de produzir movimentos analíticos tributários das aspirações homogeneizadoras, das quais não escaparam os intérpretes que abriram o século, tampouco os que participaram de seu final.

Lambert e Bastide são pontos de continuidade e não de ruptura no ciclo de autocompreensão com o qual os intelectuais identificam seus papéis, principalmente o de intelligentsia. Não bastasse a qualidade que o livro acrescenta à história das idéias no Brasil, presta ainda o serviço (erudito) de manter à mesa a atualidade de Mannheim.

Um sertão chamado Brasil recolhe ao seu interior páginas densas produzidas nas obras que deram permanência a uma representação geográfica decisiva na conformação dos debates sobre a identidade nacional brasileira. Não há quem possa, doravante, enfrentar o tema e o pantanoso terreno das idéias sem prestar contas a esse livro que, fruto de um estudo premiado com justiça, já se torna, ele mesmo, referência inescapável para todos nós.

\section{REFERÊNCIA BIBLIOGRÁFICAS}

Bastide, Roger

1971

Lambert, Jacques

1973
Brasil, terra de contrates.

São Paulo, Difel.

Dois Brasis.

São Paulo, Companhia Editora Nacional. 